\title{
From health emergency preparedness to response action: a long journey in Lebanon
}

\author{
Alissar Rady, ${ }^{1}$ Iman Shankiti, ${ }^{2}$ Richard Brennan ${ }^{3}$ and Ahmed Mandil ${ }^{4}$
}

${ }^{1}$ Senior National Professional Officer, World Health Organization, Beirut, Lebanon. ${ }^{2}$ World Health Organization Representative, Beirut, Lebanon. ${ }^{3}$ Regional Emergency Director, World Health Organization Regional Office for the Eastern Mediterranean, Cairo, Egypt. ${ }^{4}$ Coordinator, Research and Innovation, World Health Organization Regional Office for the Eastern Mediterranean, Cairo, Egypt. (Correspondence to: Alissar Rady: radya@who. int).

Citation: Rady A; Shankiti I; Brennan R; Mandil A. From health emergency preparedness to response action: a long journey in Lebanon. East Mediterr Health J. 2020;26(8):870-871. https://doi.org/10.26719/2020.26.8.870

Copyright (C) World Health Organization (WHO) 2020. Open Access. Some rights reserved. This work is available under the CC BY-NC-SA 3.0 IGO license (https://creativecommons.org/licenses/by-nc-sa/3.o/igo)

Emergency preparedness is a critical pillar of the International Health Regulations (IHR), a legally binding instrument underlying the global health security regime that came into effect in 2005 (1). Lebanon, a small country of $10452 \mathrm{~km} 2$ bordering the eastern Mediterranean (2), ratified the IHR in 2007 (3) after the devasting effects of a sudden military conflict in 2006 that severely impacted the recovering health system. Moreover, the Lebanese health system infrastructure was only just recovering from 15 years of civil war that ended in 1990 (4). Since 2005, the country has also faced a complex refugee crisis potentiating the risk of disease outbreaks since 2011 (5), in addition to a severe financial crisis that has degenerated into social unrest since October 2019, and more recently the COVID-19 pandemic since February 2020.

This constant instability, coupled with frequent security breaches, necessitated a rapid reinforcement of the health system to build its resilience and respond in an adequate and timely manner to potential and real health risks, and an almost continuous crisis mode.

Within the framework of the National Health Reform, the government progressively reaffirmed its leadership and stewardship and in the health sector. Accordingly, the Ministry of Public Health's (MoPH) capacity for disease surveillance and early warning and response rapidly increased. The primary health care (PHC) network was expanded to include more than 230 centres in 2020, and the public hospitals system was progressively expanded to reach a total of 27 hospitals by 2019, providing around $12 \%$ of total bed capacity in the country (4). More importantly, the MoPH developed and reinforced its private public partnership, adopting the Collaborative Governance approach. This approach, coupled with an accelerated IHR implementation, reinforced the health system's resilience, allowing it to withstand repeated public health shocks.

The latest public health shock caused by the Beirut port explosion resulted in more than 6000 casualties, around 180 deaths, more than 30 missing persons, in addition to an estimated 300000 residents driven out of their demolished homes, and massive economic losses estimated at US\$ 15 billion (6). The long-standing resilience of the Lebanese people and health system, anchored in the private-public partnership and fostered by the Collaborative Governance approach, allowed a rapid absorption of all casualties, although the area most affected by the blast lost around 500 beds in hospital capacity, since 3 hospitals were rendered completely nonfunctional, and 3 only partially functional. Nevertheless, the casualties - with support from the Lebanese Red Cross and the community - were rapidly referred to hospitals (private and public) outside the area affected and even outside Beirut, as needed. With WHO support, the severely damaged central warehouse was evacuated within the first 24 hours and medications safely stored in an alternative warehouse; a rapid needs assessment with cost estimation for rehabilitation of the 5 most affected hospitals was completed within 5 days from the blast; an Emergency Medical Team coordinator and a communication consultant were deployed within the first 96 hours of the explosion; and trauma and surgical supplies for 2000 patients were deployed within 26 hours (7). Such supplies were immediately distributed to the 10 hospitals that were treating the highest number of casualties. Additionally, 24 tons of personal protective equipment were also dispatched within 72 hours of the explosion. The daily situation report, initially produced for the COVID-19 outbreak, was expanded to include updates on the response to the Beirut blast, and WHO issued US\$2.2 million from its Central Fund for Emergencies within 72 hours, and outreach to donors was started immediately (7).

The support of WHO to the health sector in this unprecedented crisis was prompt. Such actions were greatly facilitated by the good rapport established by the WHO country office with the MoPH team and all health partners. A long and diversified experience of the WHO country team in public health emergencies, coupled with Country Office leadership and intense regional and headquarters teams support, reaffirmed the WHO leadership in health emergencies. Since the military aggression in Lebanon in July 2006 and the current complex crisis, a long journey of institutional capacity building in emergency preparedness and response in Lebanon has been supported by WHO. In fact, lessons 
learned from previous response to health emergencies has most likely paid off in the current structured and critical support. As stated by Benjamin Franklin in the 18th century, "By failing to prepare, you are preparing to fail" (8); preparedness is the journey to successful response.

\section{Reference}

1. The Fifty-eighth World Health Assembly. Revision of the International Health Regulations (WHA 58.3). Geneva: World Health Organization; 2005 (https://apps.who.int/gb/ebwha/pdf_files/WHA58/WHA58_3-en.pdf).

2. World Health Organization Regional Office for the Eastern Mediterranean (WHO/EMRO). Country cooperation strategy for WHO and Lebanon 2010-2015. Cairo: WHO/EMRO; 2010 (https://apps.who.int/iris/bitstream/handle/10665/113219/CCS_Lebanon_2010_EN_14483.pdf?sequence=1\&isAllowed=y).

3. World Health Organization. States parties to the International Health Regulations (2005). Geneva: World Health Organization; 2020 (https://www.who.int/ihr/legal_issues/states_parties/en/).

4. Hemadeh R; Kdouh O; Hammoud R; Jaber T; Khalek LA. The primary health care network in Lebanon: a national facility assessment. East Mediterr Health J. 2020;xx(x):xxx-xxx.https://doi.org/10.26719/emhj.20.003 (In Press).

5. Ochsenwald W. Lebanese civil war. Blacksburg: Virginia Polytechnic Institute and State University; 2020 (https://www.britannica.com/event/Lebanese-Civil-War).

6. World Health Organization Regional Office for the Eastern Mediterranean (WHO/EMRO). Situation report Lebanon Blast Issue 2. Cairo:WHO/EMRO; 2020 (http://www.emro.who.int/images/stories/lebanon/lebanon-blast-situation-report-7-8-20.pdf?ua=1).

7. World Health Organization. WHO supports emergency response in Lebanon; 2020 (https://intranet.who.int/features/emrointranetnews/).

8. Forbes quotes. Online (https://www.forbes.com/quotes/1107). 